\title{
ANÁLISES DE MEDIDAS DE CONFIABILIDADE E RISCOS EM UMA IMPRESSORA 3D
}

Izaías Jorge de Magalhães (ijm00@ hotmail.com) - Faculdade de Tecnologia / Universidade de Brasília

Túlio Costa Cavallini (cavallini.2190@gmail.com) - Faculdade de Tecnologia / Universidade de Brasília

Thalles Alves de Castro (thalles-alves@ hotmail.com) - Faculdade de Tecnologia / Universidade de Brasília

Viviane Vasconcellos Ferreira Grubisic (vivianegrubisic@unb.br) - Faculdade de Tecnologia / Universidade de Brasília

\section{RESUMO}

As impressoras 3D tem sido um dos motores para a inovação, atualmente. Tais equipamentos podem ser aplicados em diversas áreas, gerando novas soluções e modelos de negócio pelo mundo. Uma aplicação frequente é na área médica, para a qual uma empresa de Brasília-DF fornece produtos de alta complexidade geométrica. No entanto, esta nova empresa ainda não conhece a fundo o desempenho do equipamento. Neste sentido, o presente artigo objetiva estudar o desempenho de uma das impressoras que a empresa possui, por meio de medidas de confiabilidade, e identificar ações que possam aprimorar o programa de manutenção da empresa estudada. As análises mostram que a maior parte das falhas na operação da impressora se dá com poucas horas de operação, sendo notável que a alta complexidade dos modelos impressos resultam em menor confiabilidade, possivelmente em conjunto com outros fatores externos (ambiente, fatores humanos, fatores gerenciais). A função mais crítica foi o foco da aplicação de técnicas para análise de riscos, permitindo o esboço de ações para os riscos levantados.

Palavras chave: confiabilidade; impressão 3D; produtos para área biomédica; manutenção centrada em confiabilidade. 


\section{INTRODUÇÃO}

As últimas décadas podem ser marcadas pelo surgimento e popularização de tecnologias e inovações que modificaram profundamente as dinâmicas econômicas, sociais, científicas, etc. Dentre tantas tecnologias, surgiu há aproximadamente 35 anos o conceito de impressão tridimensional de objetos, segundo Gross et al. (2014). A impressão 3D tem evoluído a ponto de se tornar o motor de novos modelos de negócio e de inovações de toda sorte.

Tal tecnologia, considerada como disruptiva, pode ser utilizada nas seguintes áreas, segundo Bourell et al. (2009): design; modelagem de processos e controle; materiais, processos e máquinas; aplicações biomédicas; energia e sustentabilidade; educação.

Deve-se destacar, dentre os campos citados, as aplicações na área biomédica. A empresa foco deste trabalho é uma das pioneiras da adoção de manufatura aditiva no setor médico no Brasil, tendo sido fundada em 2010. Na área de ortopedia, está entre as empresas especializadas que oferecem pesquisa, desenvolvimento e fabricação de instrumental e fixadores externos para atendimento de emergência e correção de deformidades. No segmento de produtos customizados, a organização trabalha principalmente na confecção de biomodelos, próteses cranianas, próteses de ATM, guias ortognáticos, guias de osteotomia, moldes de construção de calotas cranianas, guias de perfuração de vértebras e outras várias aplicações.

Ela utiliza como equipamento, dentre outros modelos, as impressoras Prusa i3 MK3, sucessora da I3 MK2. Tais impressoras são bastante premiadas no segmento, além de contar com uma comunidade ativa. Elas são utilizadas principalmente para a produção de biomodelos. Dessa forma, abre-se uma gama de possibilidades para o seu uso, como diagnóstico de enfermidades e planejamento cirúrgico. A Figura 1 mostra uma imagem ilustrativa do dispositivo de impressão por filamentos, conforme publicado no manual da fabricante Prusa Research. 


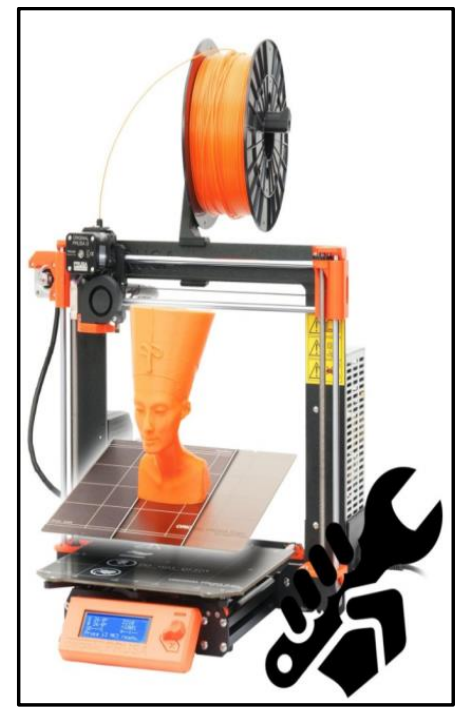

FIGURA 1 - Imagem ilustrativa da Prusa Original i3 MK3. Fonte: Prusa Research (2018).

A empresa estudada, possuindo tal equipamento, ainda não conhece plenamente todo o potencial que ela pode oferecer. Isto gera problemas na garantia da qualidade, na destinação de recursos em atividades desnecessárias, além dos que podem vir a ocorrer quando o equipamento falha. Em uma economia cada vez mais competitiva, falhas em equipamentos vitais podem significar grandes perdas para a empresa.

Dessa forma, torna-se importante conhecer e gerenciar o equipamento a fim de mitigar a probabilidade de falha dele. O conhecimento formal resultante da análise de falhas e da busca da minimização de sua ocorrência provê uma rica variedade de contextos nos quais surgem considerações acerca da confiabilidade (Fogliatto e Ribeiro, 2009). Confiabilidade, aqui, seguirá a definição de Leemis (2005):

"A confiabilidade de um item corresponde à sua probabilidade de desempenhar adequadamente o seu propósito especificado, por um determinado período de tempo e sob condições ambientais predeterminadas."

Diante do exposto, o presente trabalho objetiva realizar uma breve análise de falhas da impressora 3D Prusa i3 MK3, equipamento vital de uma empresa brasiliense que fornece produtos para a área biomédica. Ao longo deste trabalho, será melhor detalhado o objeto de estudo ao nível de funções (seção 2), serão realizadas simulações com dados de falha coletados (seção 3), além de considerações no que tange à manutenção (seção 4), seguida das considerações finais. 


\section{DEFINIÇÃO DO OBJETO DE ESTUDO}

Conforme já citado, o objeto de estudo será a impressora Prusa i3 MK3, equipamento vital para a empresa. Este imprime produtos para a área biomédica, de alta complexidade. Essa seção dedica-se a descrever o equipamento em detalhes, até o nível de funções, com base no manual do produto.

\subsection{Descrição do equipamento}

A impressora Original Prusa i3 MK3 é fabricada pela empresa Prusa Research, em Praga, República Checa. A seguir, alguns detalhes extras sobre a impressora, disponíveis no manual da fabricante.

\subsubsection{Características básicas}

a) Dimensões: $25 \times 21 \times 21 \mathrm{~cm}$;

b) Peso (bruto/ neto): 9,8 kg/ 6,3 kg (kit); $12 \mathrm{~kg} / 6,3 \mathrm{~kg}$ (impressora montada);

C) Espessura da camada: a partir de 0,05-0,35 $\mathrm{mm}$

d) Velocidade de impressão: a partir de $200 \mathrm{~mm} / \mathrm{s}$

e) Número de extrusoras (original): 1

f) Diâmetro do filamento: $1,75 \mathrm{~mm}$

g) Sensores e mecanismos anti-falha: $\operatorname{sim}$

h) Calibração: automática de 9 posições XYZ / compensação de eixos inclinados;

i) Materiais suportados: Quaisquer termoplásticos, incluindo PLA, ABS, Nylon e policarbonatos;

j) Preço Inicial (kit/montado): \$749/ \$999, de acordo com o site da empresa.

\subsubsection{Condições ambientais de uso}

a) Alimentação: 90-135 VAC, 2A / 180-264 VAC, 1A (50-60Hz);

b) Raio de temperatura: $18-38^{\circ} \mathrm{C}$, somente para uso interno;

c) Condições de umidade: $85 \%$ ou menos.

\subsection{Decomposição funcional do equipamento}

Segundo pode-se depreender de Rozenfeld et al. (2006), a modelagem funcional tem como função auxiliar a equipe de projeto a descrever os produtos em um nível abstrato. Os 
modelos funcionais permitem que o produto seja descrito por meio das suas funcionalidades, sendo uma etapa importante tanto na concepção de novos produtos quanto na engenharia reversa de produtos já existentes. Como resultado final, obtém-se as funções posicionadas em um fluxo de energia, material e sinais. Semanticamente, uma função é modelada por um par "verbo+substantivo" (Gomes Ferreira, 1997).

\subsubsection{Função Total}

De acordo com Gomes Ferreira (1997), uma função total é aquela na qual se expressa a relação entre entradas e saídas do sistema, e pode ser decomposta em funções de menor complexidade. No caso do presente artigo, a função "Imprimir objetos em 3D" é a função global do equipamento. A Figura 2 mostra a função total do produto.

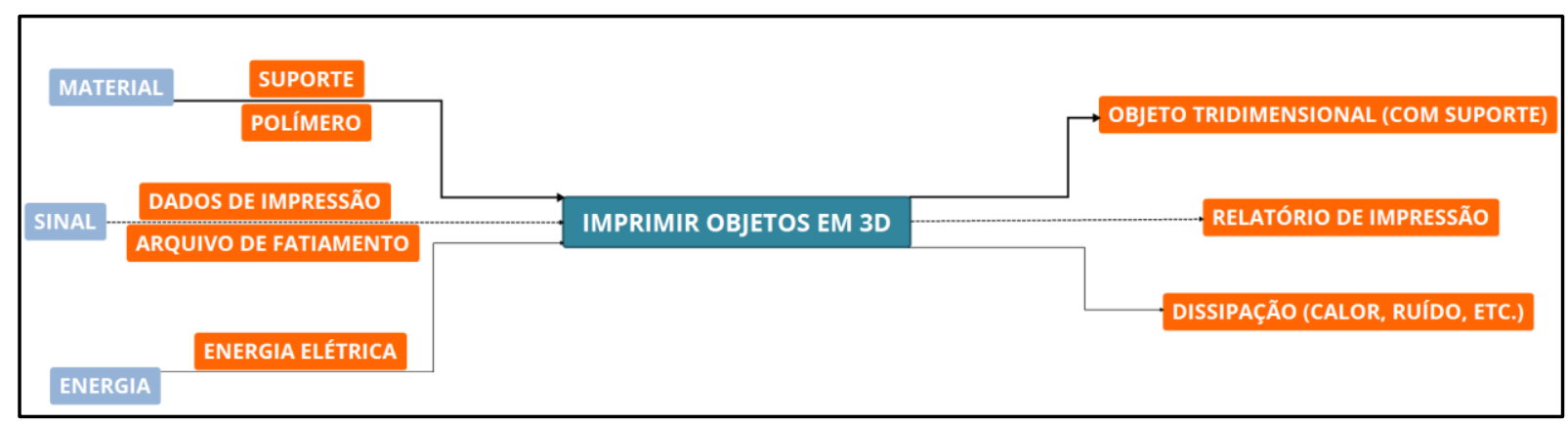

FIGURA 2 - Função global. Fonte: Os autores

A figura anterior mostra que a função global tem como entradas de materiais o suporte (objeto para evitar deformação do produto a ser impresso) e o polímero a ser transformado. Soma-se ao material os dados de impressão e o arquivo de fatiamento (sinais), além da energia elétrica (energia). Após a execução da função global, obtém-se o objeto tridimensional ainda junto com o suporte (material), o relatório de impressão (sinal), e a energia dissipada durante o processo de transformação.

\subsubsection{Funções Elementares}

Após a definição da função global, decompõe-se o produto em funções elementares. $\mathrm{O}$ resultado gráfico para a impressora 3D está no Apêndice A. Assim, listam-se as subfunções elencadas para o projeto:
a) Alimentar Cabeçote
b) Fundir Filamento
c) Depositar Polímero na Mesa 

d) Solidificar Objeto 3D
e) Inserir Dados de Impressão
f) Movimentar Mesa
g) Movimentar cabeçote
h) Manter Temperatura

\subsubsection{Interação com usuário e meio ambiente}

Segundo o manual do fabricante, a interação com o usuário se dá por meio de um painel LCD, com botões. Além disso, há uma entrada USB para conectividade com outros dispositivos, e slot para cartão SD a fim de que se possa também inserir dados. Também existem softwares que realizam a interação humana via computador.

Já a interação da impressora com o meio ambiente, notam-se algumas restrições. Além das já elencadas no item 2.1.2, ressalta-se que a operação deve se dar em ambiente indoor. $\mathrm{O}$ equipamento não pode ser exposto a condições que podem ocorrer ao ar livre, como chuva, neve, sol intenso, etc.

\section{MEDIDAS DE CONFIABILIDADE}

Uma breve lista de dados é capaz de revelar várias informações acerca da confiabilidade do equipamento, enquanto opera na empresa. A única variável coletada foi o tempo até a falha, em $n$ observações. Dos dados, é possível gerar gráficos (histogramas) de densidade de falha, taxa de falha, confiabilidade, e distribuição acumulada de falha. Ajusta-se depois a melhor distribuição de probabilidades para os dados, a fim de prosseguir com as análises a partir de simulações de Monte Carlo. Toda a geração de resultados para análise foi realizada pelo software ProConf 2000 (ProConf, 2000).

\subsection{Tempos até falha do sistema}

Os dados de entrada para o estudo de confiabilidade da impressora 3D foram coletados na empresa, por meio de investigação dos registros em atas, além de informações prestadas por colaboradores, durante o segundo semestre de 2018. Ressalta-se que a empresa não tratava tais dados da maneira devida, sendo necessária recordatória junto aos informantes para que fosse completado o número mínimo de 30 observações. Os tempos até a falha (TTF, time to failure) são apresentados na Tabela 1.

TABELA 1 - Medidas de tempos até falha 


\begin{tabular}{|c|c|c|c|}
\hline Observação & $\begin{array}{c}\text { Tempo até a } \\
\text { falha (em horas) }\end{array}$ & Observação & $\begin{array}{c}\text { Tempo até a } \\
\text { falha (em horas) }\end{array}$ \\
\hline $\mathbf{1}$ & 12 & $\mathbf{1 6}$ & 35 \\
\hline $\mathbf{2}$ & 4 & $\mathbf{1 7}$ & 91 \\
\hline $\mathbf{3}$ & 3 & $\mathbf{1 8}$ & 13 \\
\hline $\mathbf{4}$ & 2,5 & $\mathbf{1 9}$ & $\mathbf{5}$ \\
\hline $\mathbf{5}$ & 30 & $\mathbf{2 0}$ & 38 \\
\hline $\mathbf{6}$ & 37 & $\mathbf{2 1}$ & 35 \\
\hline $\mathbf{7}$ & 41 & $\mathbf{2 2}$ & 63 \\
\hline $\mathbf{8}$ & 30 & $\mathbf{2 3}$ & 12 \\
\hline $\mathbf{9}$ & 21 & $\mathbf{2 4}$ & 15 \\
\hline $\mathbf{1 0}$ & 26 & $\mathbf{2 5}$ & 60 \\
\hline $\mathbf{1 1}$ & 3 & $\mathbf{2 6}$ & 44 \\
\hline $\mathbf{1 2}$ & 7 & $\mathbf{2 7}$ & 12 \\
\hline $\mathbf{1 3}$ & 46 & $\mathbf{2 8}$ & $\mathbf{5 4}$ \\
\hline $\mathbf{1 4}$ & 9 & $\mathbf{2 9}$ & 39 \\
\hline $\mathbf{1 5}$ & 39 & $\mathbf{3 0}$ & 27 \\
\hline
\end{tabular}

No software ProConf 2000, os tempos foram hierarquizados para a geração dos histogramas e gráficos que serão mostrados adiante, com confiança de 95\%. Desde já, é perceptível que ocorrem falhas em curtos períodos de duração, não havendo na Tabela 1 nenhum tempo de operação contínua superior a 100 horas.

Confrontando-se com os períodos recomendados para manutenção regular, de acordo o manual, em que o tempo médio entre reparos de rotina é cerca de 200 horas, percebe-se que o equipamento tem tido um desempenho abaixo do esperado.

\subsection{Simulações com os dados}

Os histogramas gerados pelo software serão apresentados na subseção 3.2.1. Na subseção 3.2.2, busca-se a melhor distribuição para o conjunto de dados de entrada, onde uma será escolhida para análises mais aprofundadas.

\subsubsection{Histogramas gerados}

O software ProConf 2000 possui 4 funções para a geração de gráficos baseados nos dados informados anteriormente. A primeira da lista é a função "Frequência", equivalente à densidade de falhas, mostrada no Gráfico 1. O Gráfico 2 seguinte mostra o resultado para a função "Taxa de Falha”. O próximo histograma, Gráfico 3, reflete a confiabilidade do sistema ao longo do tempo. Por fim, temos a função "Densidade Acumulada de Falha”, no Gráfico 4. 


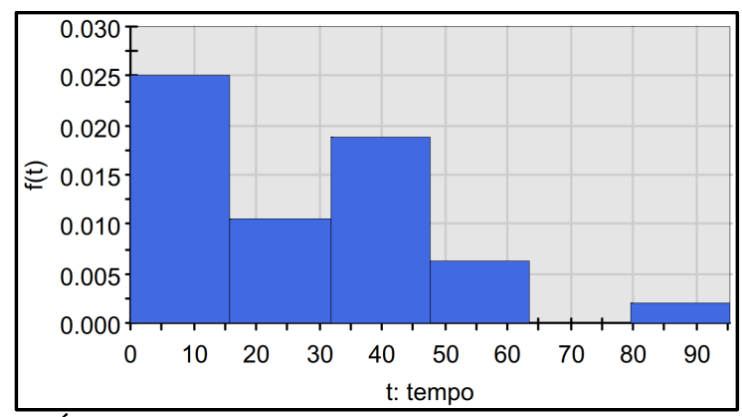

GRÁFICO 1 - Densidade de falhas. Fonte: Os autores

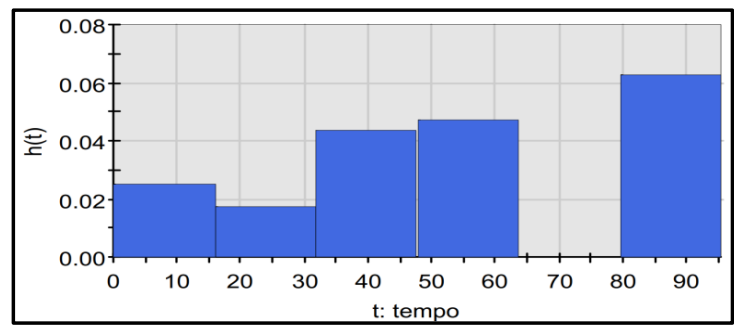

GRÁFICO 2 - Taxa de falha. Fonte: Os autores

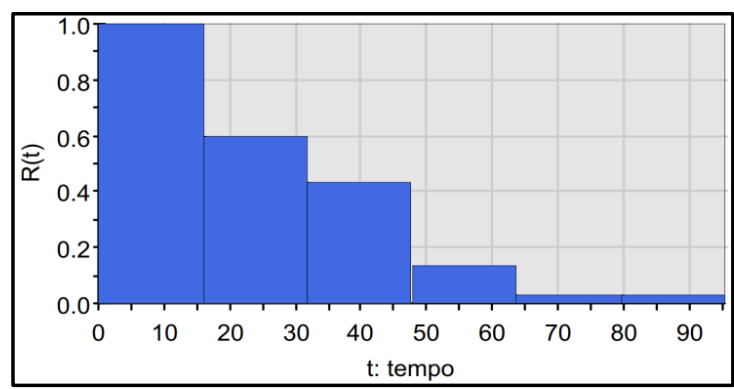

GRÁFICO 3 - Confiabilidade. Fonte: Os autores

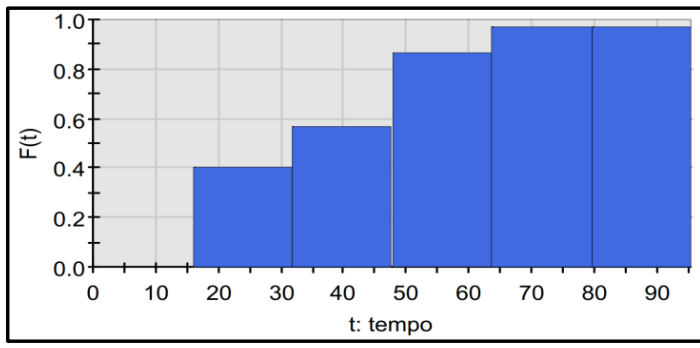

GRÁFICO 4 - Densidade acumulada de falhas. Fonte Os autores

Observa-se no Gráfico 1 que as falhas se dão majoritariamente logo no início da operação, região de maior densidade. Contudo, se o equipamento passa por essa fase sem erros, observa-se que as falhas diminuem.

A variável $h(t)$, no Gráfico 2, significa o risco de se estar operando a máquina ao longo do tempo. É observado que ele é crescente ao longo do tempo, desconsiderando-se o "eclipse 
de falhas" entre 65 e 80 horas de operação. Tendo $h(t)$ tendência crescente, portanto não constante, é possível descartar a hipótese de que o sistema segue uma distribuição exponencial para as falhas.

É notório o quanto a confiabilidade do equipamento decai passado pouco tempo de operação (Gráfico 3). Deve-se estar bastante atento a este fato e mitigar os riscos associados a partir dessa informação. No momento, deve-se esperar falhas frequentes e sempre ter um plano de contingência para os problemas associados.

A função acumulada de falhas (Gráfico 4) revela que as falhas apresentam um salto abrupto já no início das operações. O crescimento é rápido até se estabilizar já na quase totalidade.

\subsubsection{Distribuição mais apropriada}

Para prosseguir com as análises, baseadas em simulação de Monte Carlo, busca-se adequar o conjunto de dados à melhor distribuição de probabilidades. Os papéis de probabilidade, apresentados nos Gráficos 5 a 8, mostram os dados confrontados com a reta da distribuição.

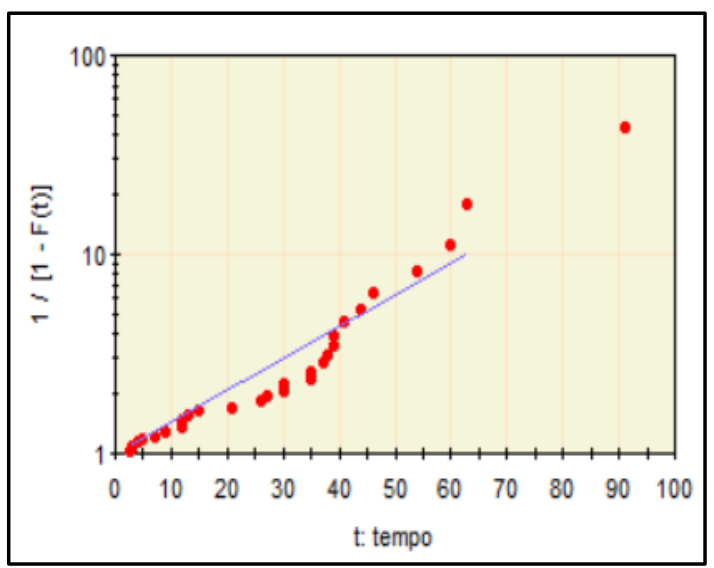

GRÁFICO 5 - Papel de probabilidade para Distribuição Exponencial. Fonte: Os autores 


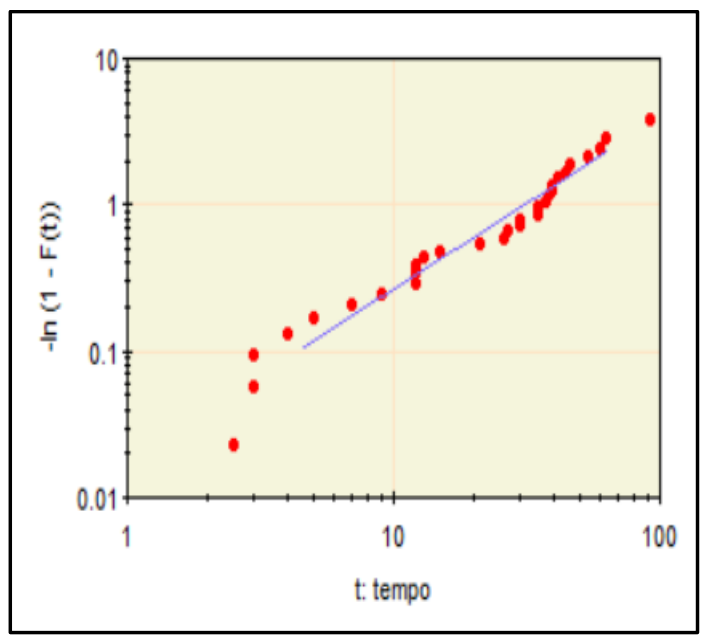

GRÁFICO 6 - Papel de probabilidade para Distribuição de Weibull. Fonte: Os autores

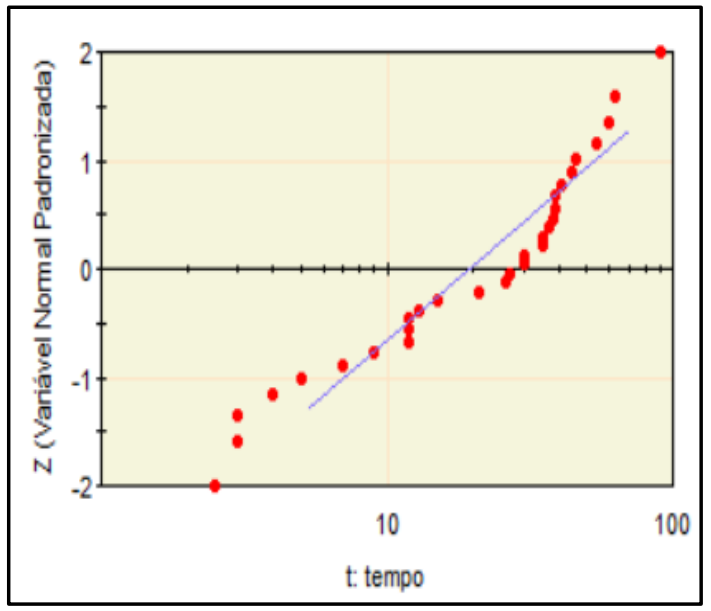

GRÁFICO 7 - Papel de probabilidade para Distribuição Lognorma. Fonte: Os autores

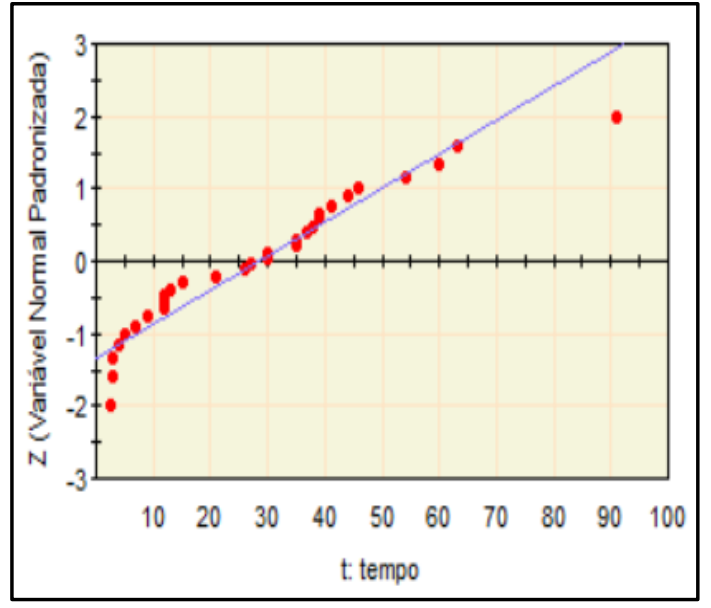

GRÁFICO 8 - Papel de probabilidade para Distribuição Normal. Fonte: Os autores

Analisando graficamente, é possível checar que os ajustes Exponencial e de Weibull (Gráficos 5 e 6) são os que melhor se aproximam da reta. Como já foi registrado, o ajuste 
Exponencial foi descartado pelo fato de a impressora apresentar risco crescente. Dessa forma, a distribuição de Weibull é a que melhor se adequa.

\subsubsection{Simulações com a distribuição de Weibull}

Por meio do ajuste para a distribuição de Weibull, feita através do software Proconf 2000, obteve-se os valores estimados dos parâmetros da distribuição. Serão apresentados os valores para estimativa não tendenciosa:

a) Parâmetro de escala $(\gamma): 1,2505$

b) $\operatorname{Var}(\gamma): 0,0354$

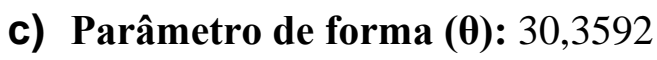

O software, com base nos parâmetros, realiza simulações de Monte Carlo para traçar os gráficos da distribuição de Weibull para o conjunto de dados informado. O resultado é apresentado nos Gráficos 9 a 12.

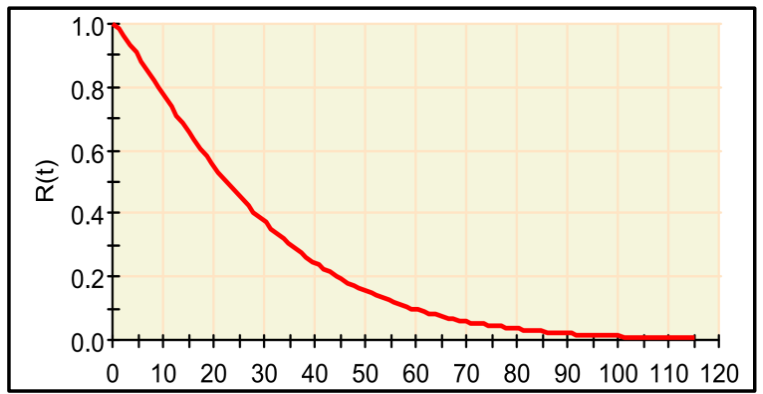

GRÁFICO 9 - Confiabilidade. Fonte: Os autores

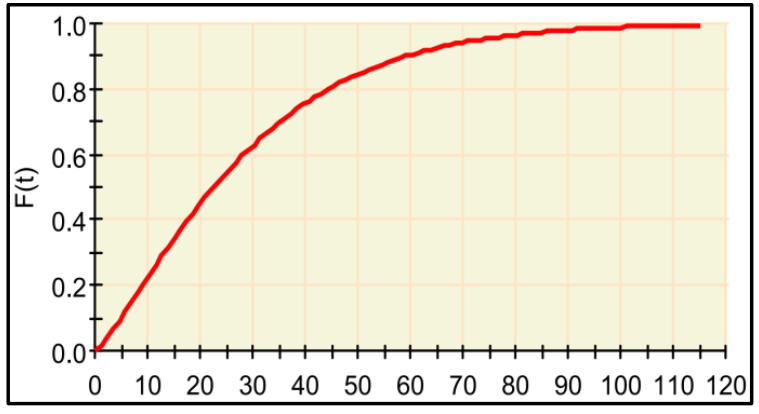

GRÁFICO 10 - Distribuição acumulada de falhas. Fonte: Os autores

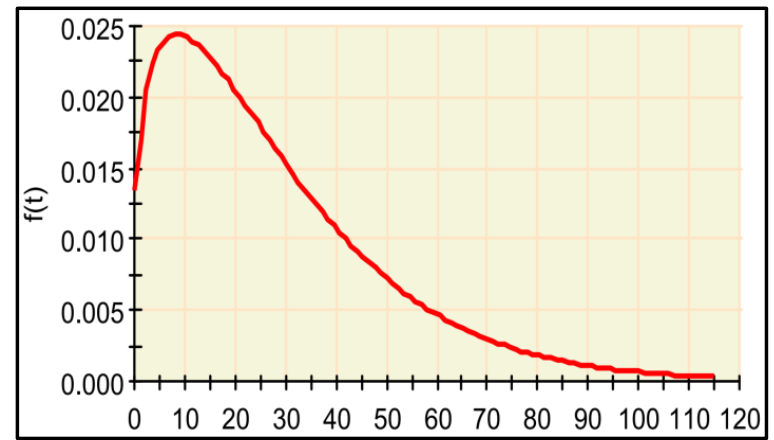




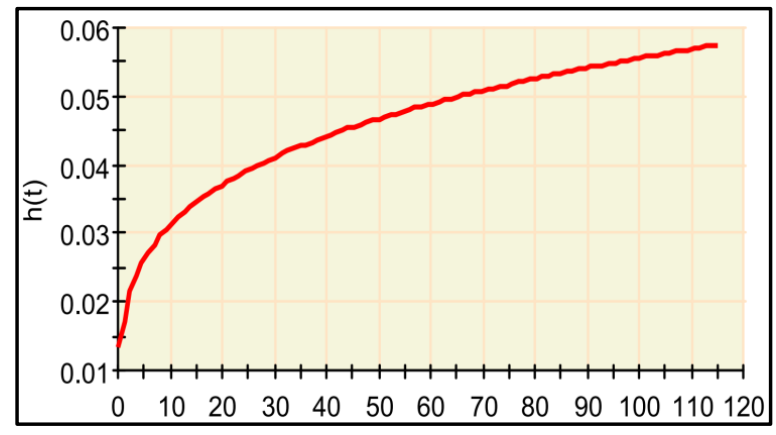

GRÁFICO 12 - Taxa de falha. Fonte: Os autores

As simulações trazem uma continuidade maior ao conjunto de dados, deixando mais claras as tendências já apresentadas. Dessa forma, corrobora-se o que foi visualizado nos dados brutos com a distribuição. Além disso, obtém-se outras medidas importantes:

a) Tempo para que $10 \%$ das falhas ocorram: $5,02 \mathrm{~h}$

b) Tempo para que 50\% das falhas ocorram: $22,64 \mathrm{~h}$

c) Tempo médio entre falhas: $28,27 \mathrm{~h}$, com desvio padrão de $22,75 \mathrm{~h}$. Logo, esta medida é bastante imprecisa.

\subsubsection{Informações sobre a confiabilidade do equipamento}

Um último recurso do software ProConf 2000 é a calculadora de confiabilidade. Com base em tudo o que foi levantado, ela calcula a confiabilidade do objeto de estudo em determinado tempo de operação, e vice-versa. Por meio dessa ferramenta é possível obter informações sobre o desempenho da máquina para qualquer tempo do intervalo analisado.

Notou-se que o tempo de operação para que a confiabilidade seja igual ou superior a 0,90 deve ser igual ou inferior a 5 horas. O ponto onde se dá a situação de flip coin (confiabilidade de 50\%) é 22,64 horas. No limite, levaria-se 6000 horas de operação para que a confiabilidade seja 0,00 .

Dessa forma, é possível dizer que os tempos de operação são muito curtos para que haja alguma falha. Segundo a empresa, as principais falhas são relacionadas à adesão do material na mesa (leito de aquecimento) e/ou no descolamento de camadas. Ou seja, fatores externos à máquina em si, juntamente à complexidade dos produtos, podem estar interferindo em valores tão baixos de confiabilidade.

Para se calcular a confiabilidade do sistema, deve-se atribuir valores para a confiabilidade de cada componente integrante dos subsistemas. Baseado nas informações 
sobre a confiabilidade do equipamento obtidas do software, optou-se por atribuir valores baseados para confiabilidade com $15 \mathrm{~h}$ de operação $(0,6609)$. As confiabilidades para cada subfunção estão mostradas na Tabela 2, seguinte.

TABELA 2 - Valores de confiabilidade atribuídas às subfunções

\begin{tabular}{|l|l|}
\hline \multicolumn{1}{|c|}{ Sub funções } & \multicolumn{1}{c|}{ Confiabilidade (R) } \\
\hline Alimentar Cabeçote & 0,5522 \\
\hline Fundir Filamento & 0,6371 \\
\hline Depositar Polímero na Mesa & 0,5569 \\
\hline Solidificar Objeto 3D & 0,3566 \\
\hline Inserir Dados de Impressão & 0,9344 \\
\hline Movimentar Mesa & 0,6875 \\
\hline Movimentar cabeçote & 0,7629 \\
\hline Manter Temperatura & 0,7816 \\
\hline
\end{tabular}

A confiabilidade do sistema, obtida a partir do produto das confiabilidades individuais das funções, foi de 0,02334 .

A medida de importância de cada componente também é simplificada para um sistema em série. O componente com menor confiabilidade certamente será o mais crítico, conforme entendimento obtido a partir de Fogliatto e Ribeiro (2009). Dessa forma, temos a subfunção "solidificar objeto 3D" como a mais crítica, seguida de outras subfunções relacionadas à gestão de temperaturas ao longo do processo de impressão.

\section{ANÁLISES DE RISCOS E MANUTENÇÃo}

Todas as informações anteriormente levantadas servirão de base para as análises de riscos, e orientações passíveis de serem consideradas pela organização no sentido de aprimorar a manutenção dos equipamentos. O propósito desta seção é identificar ações que possam aprimorar o programa de manutenção da empresa estudada. Para isso, das subseções 
4.1 a 4.3, serão aplicadas as técnicas Hazard and Operability Study (HAZOP), Event Tree Analysis (ETA), e Failure Modes and Effects Analysis (FMEA), além de considerações sobre a Manutenção Centrada em Confiabilidade (MCC), respectivamente. No âmbito do presente trabalho, não serão abordadas todas as etapas do processo, mas somente a fase mais crítica: a fase de solidificação dos objetos impressos.

\subsection{HAZOP aplicado ao componente mais crítico}

A técnica denominada HAZOP - Análise de Perigos e Operabilidade - é uma análise sistemática de como os desvios sobre especificações prévias em um sistema podem emergir, e se tais desvios podem resultar em perigos (WINTHER, et al, 2001). Esta metodologia é baseada em um procedimento que gera perguntas de maneira estruturada e sistemática através do uso apropriado de um conjunto de palavras-guia (Diniz et al. 2006). O segmento estudado foi a solidificação dos objetos, de onde emergem a maior parte das falhas. O estudo é representado nas Tabelas 3 e 4. Na Tabela 3, são levantados os desvios, seguidos das análises que os avaliam em função dos seus efeitos, proteções existentes, e prioridade. Ao fim, são propostas recomendações. A Tabela 4 é uma legenda da Tabela 3, para auxílio na definição da categoria de risco.

TABELA 3 - HAZOP aplicado

\begin{tabular}{|c|c|c|c|c|c|c|c|c|c|c|}
\hline \multirow{2}{*}{$\begin{array}{c}\text { Palavra } \\
\text { Guia }\end{array}$} & \multirow{2}{*}{ Parâmetros } & \multirow{2}{*}{\multicolumn{2}{|c|}{ Desvio }} & \multirow{2}{*}{ Possiveis Causas } & \multirow{2}{*}{ Efeitos } & \multirow{2}{*}{$\begin{array}{l}\text { Proteçōes } \\
\text { Existentes }\end{array}$} & \multicolumn{3}{|c|}{ RISCO } & \multirow{2}{*}{$\begin{array}{l}\text { Recomendações e } \\
\text { Observaçōes }\end{array}$} \\
\hline & & & & & & & Frequência & Severidade & Cat. Risco & \\
\hline \multirow{3}{*}{$\begin{array}{c}\text { Pouco ou } \\
\text { nenhum }\end{array}$} & \multirow{3}{*}{ Suporte } & \multirow{3}{*}{1} & \multirow{3}{*}{$\begin{array}{l}\text { Pouco ou nenhum } \\
\text { suporte expelido }\end{array}$} & Entupimento do bico extrusor & \multirow{3}{*}{$\begin{array}{c}\text { Construção de sólido } \\
\text { amorfo }\end{array}$} & $\begin{array}{l}\text { Verificação do bico } \\
\text { extrusor antes de } \\
\text { iniciar a impressão }\end{array}$ & \multirow{3}{*}{3} & \multirow{3}{*}{ PR } & & $\begin{array}{l}\text { Instação de } \\
\text { mecanismo de } \\
\text { alarme de } \\
\text { entupimento }\end{array}$ \\
\hline & & & & $\begin{array}{l}\text { Falha na programação da } \\
\text { impressão }\end{array}$ & & \multirow[t]{2}{*}{$\begin{array}{l}\text { Verificação se há } \\
\text { filamento de } \\
\text { suporte suficiente }\end{array}$} & & & & $\begin{array}{l}\text { Instalação de } \\
\text { mecanismo de } \\
\text { alarme para falta } \\
\text { de filamento }\end{array}$ \\
\hline & & & & Falta de filamento de suporte & & & & & & Duplo-check do stl \\
\hline \multirow{2}{*}{ Ocorrer } & \multirow{2}{*}{ Movimentação } & \multirow[b]{2}{*}{2} & \multirow[b]{2}{*}{ Deslocamento do sólido } & $\begin{array}{c}\text { Colisão do bico com o sólido } \\
\text { impresso }\end{array}$ & \multirow{2}{*}{$\begin{array}{l}\text { Desalinhamento das } \\
\text { camadas do sólido }\end{array}$} & \multirow[b]{2}{*}{ - } & \multirow[b]{2}{*}{3} & \multirow[b]{2}{*}{ PR } & & \multirow[b]{2}{*}{ Duplo-check do st } \\
\hline & & & & $\begin{array}{c}\text { Falha na programação da } \\
\text { impressão }\end{array}$ & & & & & & \\
\hline \multirow{2}{*}{ Pouca } & \multirow{2}{*}{ Adesão } & \multirow{2}{*}{3} & \multirow{2}{*}{$\begin{array}{l}\text { Pouca adesão da } \\
\text { primeira camada }\end{array}$} & $\begin{array}{l}\text { Limpeza ineficaz da mesa de } \\
\text { impressão }\end{array}$ & $\begin{array}{l}\text { Descolamento da } \\
\text { primeira camada }\end{array}$ & $\begin{array}{c}\text { Aplicação de spray } \\
\text { laquê }\end{array}$ & \multirow{2}{*}{4} & \multirow{2}{*}{ PR } & & \multirow{2}{*}{\begin{tabular}{|c|}
$\begin{array}{c}\text { Aplicação de spray } \\
\text { próprio para } \\
\text { impressão 3D }\end{array}$ \\
$\begin{array}{c}\text { Limpeza antes de } \\
\text { cada impressão }\end{array}$
\end{tabular}} \\
\hline & & & & $\begin{array}{l}\text { Não aplicação do spray de } \\
\text { adesão }\end{array}$ & $\begin{array}{l}\text { Empenamento da } \\
\text { primeira camada }\end{array}$ & $\begin{array}{l}\text { Limpeza periódica } \\
\text { da mesa de } \\
\text { impressão }\end{array}$ & & & & \\
\hline \multirow{2}{*}{ Muita } & \multirow{2}{*}{ Temperatura } & \multirow{2}{*}{4} & \multirow{2}{*}{$\begin{array}{l}\text { Temperatura excessiva } \\
\text { do filamento }\end{array}$} & $\begin{array}{l}\text { Falha no cooler de } \\
\text { resfriamento do sólido }\end{array}$ & \multirow{2}{*}{$\begin{array}{l}\text { Derretimento das } \\
\text { camadas }\end{array}$} & 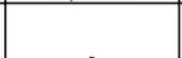 & 2 & $P R$ & & $\begin{array}{l}\text { Revisão periódica } \\
\text { dos sensores de }\end{array}$ \\
\hline & & & & $\begin{array}{c}\text { Falha no sensor de } \\
\text { temperatura }\end{array}$ & & $\cdot$ & 2 & $\mathrm{PR}$ & & $\begin{array}{c}\text { temperatura e } \\
\text { cooler. }\end{array}$ \\
\hline Muita & Temperatura & 5 & $\begin{array}{c}\text { Temperatura excessiva } \\
\text { do ambiente }\end{array}$ & Fator ambiental & $\begin{array}{c}\text { Derretimento das } \\
\text { camadas }\end{array}$ & Sala fechada & 1 & PR & & $\begin{array}{l}\text { Uso de cúpula de } \\
\text { acrílico }\end{array}$ \\
\hline Pouca & Temneratura & 6 & Temperatura muito & Fator ambiental & $\begin{array}{c}\text { Contração das } \\
\text { camadas }\end{array}$ & & & PR & & Uso de cúpula de \\
\hline Pouca & Temperatura & 6 & baixa do ambiente & $\begin{array}{l}\text { Falta de isolante térmico } \\
\text { (cúpula) }\end{array}$ & $\begin{array}{c}\text { Empenamento das } \\
\text { camadas }\end{array}$ & Sala fechada & 2 & $P R$ & & acrílico \\
\hline
\end{tabular}

TABELA 4 - Legenda da Tabela 3.1 


\begin{tabular}{|c|c|c|c|c|}
\hline \multicolumn{5}{|c|}{ Matriz de Aceitabilidade de Risco } \\
\hline $\begin{array}{c}\text { Severidade / } \\
\text { Frequência }\end{array}$ & Remoto (RE) & Ocasional (OC) & Provável (PR) & Frequente (FR) \\
\hline $\begin{array}{c}\text { Catastrófica } \\
\text { (4) }\end{array}$ & & & 3 & \\
\hline $\begin{array}{c}\text { Alta } \\
\text { (3) }\end{array}$ & & & 1 e 2 & \\
\hline $\begin{array}{c}\text { Média } \\
\text { (2) }\end{array}$ & & & 4 e 6 & \\
\hline $\begin{array}{c}\text { Leve } \\
\text { (1) }\end{array}$ & & & 5 & \\
\hline
\end{tabular}

Depreende-se da análise aplicada ao processo de impressão 3D, que há riscos difíceis de serem minimizados a um nível considerável devido ao fato de o processo de solidificação e de resfriamento ser instável para a geometria desejada. É importante destacar que a microestrutura sofre com a variação de condicionantes que não necessariamente foram detectadas no processo, e também ressalta-se que a variação de temperatura, umidade e um possível entupimento do bico extrusor contribuem significativamente para dificultar o processo. Dentre as recomendações mais importantes, destacam-se a necessidade de instalar mecanismos que alertem sobre o entupimento do bico extrusor e a falta de filamento, além de se indicar o uso do spray adequado para a limpeza da mesa de impressão.

\subsection{ETA para o projeto}

Uma árvore de eventos (ETA) é uma construção gráfica que descreve a sequência de ocorrência de eventos em um sistema lógico. A árvore identifica possíveis efeitos e contém estimativas das probabilidades de ocorrência (LACASSE et al, 2014). A ETA é uma técnica aplicável a sistemas físicos (com ou sem operadores humanos) e sistemas de tomada de decisão/ gerenciamento. Como a impressora 3D pode ser considerada um sistema físico, aplicou-se a ETA (Figuras 3 e 4 ) para a função mais crítica. 


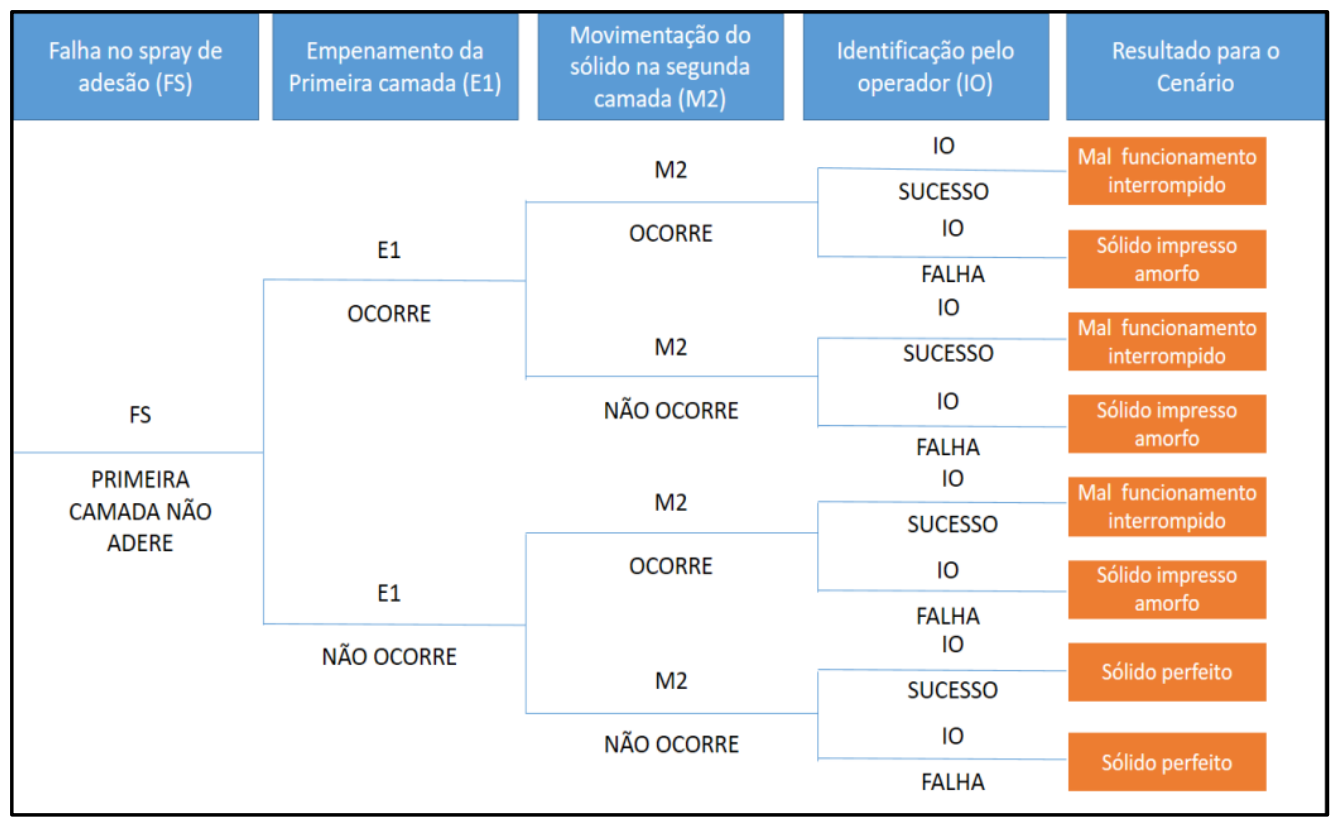

FIGURA 3 - ETA, sem os valores de probabilidade. Fonte: Os autores

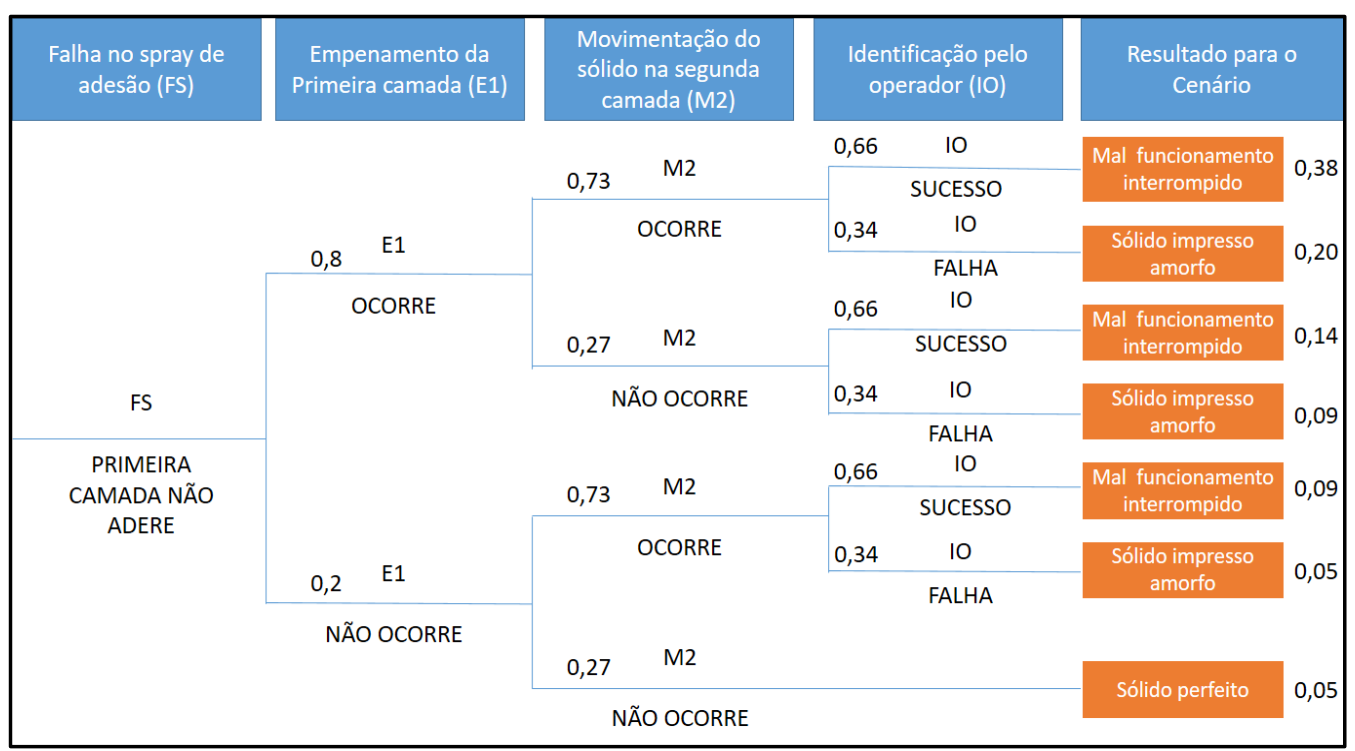

FIGURA 4 - ETA, com os valores de probabilidade. Fonte: Os autores

A partir das Figuras 4.1 e 4.2 , pode-se concluir que a ETA evidencia que grande parte do insucesso do processo é atribuído em maior parte a interrupção do bico extrusor. Também há a necessidade de ser sinalizado se esta interrupção é causada por um problema que remete ao próprio material ou mesmo às próprias condições a que a máquina está submetida.

\subsection{Manutenção Centrada em Confiabilidade (MCC)}

Fogliatto e Ribeiro (2009) definem a MCC como um programa que reúne várias técnicas de engenharia para assegurar que os equipamentos de uma planta fabril continuarão 
realizando as funções especificadas. Moubray (1997) estipula sete questões fundamentais a serem contempladas pelos programas de MCC:

a) Quais as funções e padrões de desempenho esperados para os equipamentos fabris?

b) De que modo os equipamentos podem falhar em cumprir suas funções?

c) O que causa cada falha funcional?

d) O que acontece quando cada falha ocorre?

e) De que forma cada falha interessa?

f) O que pode ser feito para prevenir ou impedir cada falha?

g) $\mathrm{O}$ que deve ser feito quando não pode ser estabelecida uma atividade pró-ativa pertinente?

Das questões anteriores, é possível notar que existe certa relação de simbiose entre MCC e FMEA (Failure Modes and Effects Analysis, Análise dos Modos de Falha e seus Efeitos). Segundo Rozenfeld (2006), a análise consiste na formação de um grupo de pessoas que possam identificar, para o produto ou processo em questão, suas funções, tipos de falhas que possam ocorrer, efeitos e possíveis causas dessa falha. A seguir, os riscos são de cada causa são avaliados por meio de índices (severidade, ocorrência e detecção, avaliados em escala de 1 a 10), e com base nessa avaliação serão tomadas medidas de forma a diminuir a incidência desses riscos, aumentando a confiabilidade do produto e/ou processo. Neste sentido, aplicou-se a técnica FMEA para a função mais crítica, conforme mostrado na Tabela 5.

TABELA 5 - FMEA para a função "Solidificação de objeto 3D 


\begin{tabular}{|c|c|c|c|c|c|c|c|c|c|c|c|c|}
\hline Produto & Subsistema & & Modo de Falha & Efeitos & $s$ & Causa Potencial & $0 \mid$ & $\begin{array}{c}\text { Controle } \\
\text { preventivo atual }\end{array}$ & $\begin{array}{c}\text { Controle Deteç̧ão } \\
\text { atual }\end{array}$ & D & NRP & $\begin{array}{c}\text { Recomendações e } \\
\text { Observações }\end{array}$ \\
\hline \multirow{11}{*}{$\begin{array}{l}\frac{m}{\Sigma} \\
\frac{\pi}{g} \\
\frac{x}{\alpha}\end{array}$} & \multirow{11}{*}{$\begin{array}{l}\text { Solidificação } \\
\text { do objeto 3D }\end{array}$} & \multirow{3}{*}{1} & \multirow{3}{*}{$\begin{array}{l}\text { Pouco ou } \\
\text { nenhum suporte } \\
\text { expelido }\end{array}$} & \multirow{3}{*}{$\begin{array}{l}\text { Construção de } \\
\text { sólido amorfo }\end{array}$} & \multirow{3}{*}{8} & $\begin{array}{l}\text { Entupimento do } \\
\text { bico extrusor }\end{array}$ & \multirow{3}{*}{7} & $\begin{array}{l}\text { Verificação do bico } \\
\text { extrusor antes de } \\
\text { iniciar a impressão }\end{array}$ & $\begin{array}{c}\text { Inspeção visual } \\
\text { aleatoriamente } \\
\text { ordenada }\end{array}$ & \multirow{3}{*}{5} & \multirow{3}{*}{280} & $\begin{array}{c}\text { Instação de mecanismo } \\
\text { de alarme de } \\
\text { entupimento }\end{array}$ \\
\hline & & & & & & $\begin{array}{l}\text { Falha na } \\
\text { programação da } \\
\text { impressão }\end{array}$ & & \multirow{2}{*}{$\begin{array}{l}\text { Verificação se há } \\
\text { filamento de } \\
\text { suporte suficiente }\end{array}$} & \multirow{2}{*}{$\begin{array}{c}\text { Após parada } \\
\text { desmontagem do } \\
\text { bico }\end{array}$} & & & $\begin{array}{c}\text { Instalação de } \\
\text { mecanismo de alarme } \\
\text { para falta de filamento }\end{array}$ \\
\hline & & & & & & $\begin{array}{l}\text { Falta de filamento } \\
\text { de suporte }\end{array}$ & & & & & & Duplo-check do stl \\
\hline & & \multirow{2}{*}{\multicolumn{2}{|c|}{$2 \begin{array}{l}\text { Deslocamento do } \\
\text { sólido }\end{array}$}} & \multirow{2}{*}{$\begin{array}{c}\text { Desalinhamento } \\
\text { das camadas do } \\
\text { sólido }\end{array}$} & \multirow[b]{2}{*}{8} & $\begin{array}{c}\text { Colisão do bico com } \\
\text { o sólido impresso }\end{array}$ & \multirow[b]{2}{*}{7} & & \multirow{2}{*}{$\begin{array}{l}\text { Inspeção visual } \\
\text { aleatoriamente } \\
\text { ordenada }\end{array}$} & \multirow[b]{2}{*}{4} & \multirow[b]{2}{*}{224} & \multirow[b]{2}{*}{ Duplo-check do stl } \\
\hline & & & & & & $\begin{array}{l}\text { Falha na } \\
\text { programaçãa da } \\
\text { impressão }\end{array}$ & & - & & & & \\
\hline & & \multirow[b]{2}{*}{3} & \multirow[b]{2}{*}{$\begin{array}{l}\text { Pouca adesão da } \\
\text { primeira camada }\end{array}$} & $\begin{array}{r}\text { Descolamento da } \\
\text { primeira camada }\end{array}$ & & $\begin{array}{l}\text { Limpeza ineficaz da } \\
\text { mesa de impressão }\end{array}$ & \multirow[b]{2}{*}{9} & $\begin{array}{l}\text { Aplicação de spray } \\
\text { laquê }\end{array}$ & \multirow{2}{*}{$\begin{array}{c}\text { Operador } \\
\text { acompanha a } \\
\text { impressão da } \\
\text { primeira camada } \\
\text { até a sua conclusão }\end{array}$} & \multirow[b]{2}{*}{7} & \multirow[b]{2}{*}{504} & $\begin{array}{c}\text { Aplicação de spray } \\
\text { próprio para impressão }\end{array}$ \\
\hline & & & & $\begin{array}{l}\text { Empenamento da } \\
\text { primeira camada }\end{array}$ & 8 & $\begin{array}{l}\text { Não aplicação do } \\
\text { spray de adesão }\end{array}$ & & \begin{tabular}{|c|} 
Limpeza periódica \\
da mesa de \\
impressão
\end{tabular} & & & & $\begin{array}{l}\text { Limpeza antes de cada } \\
\text { impressão }\end{array}$ \\
\hline & & 4 & $\begin{array}{l}\text { Temperatura } \\
\text { excessiva do } \\
\text { filamento }\end{array}$ & $\begin{array}{l}\text { Derretimento das } \\
\text { camadas }\end{array}$ & 7 & $\begin{array}{c}\begin{array}{c}\text { Falha no cooler de } \\
\text { resfriamento do } \\
\text { sólido }\end{array} \\
\begin{array}{c}\text { Falha no sensor de } \\
\text { temperatura }\end{array} \\
\end{array}$ & 6 & - & $\begin{array}{c}\text { Marcador de } \\
\text { temperatura no } \\
\text { painel de controle }\end{array}$ & 8 & 336 & $\begin{array}{l}\text { Revisão periódica dos } \\
\text { sensores de } \\
\text { temperatura e cooler. }\end{array}$ \\
\hline & & 5 & $\begin{array}{l}\text { Temperatura } \\
\text { excessiva do } \\
\text { ambiente }\end{array}$ & $\begin{array}{l}\text { Derretimento das } \\
\text { camadas }\end{array}$ & 6 & Fator ambiental & 4 & Sala fechada & $\begin{array}{l}\text { Termômetro na } \\
\text { parede }\end{array}$ & 4 & 96 & $\begin{array}{l}\text { Uso de cúpula de } \\
\text { acrílico }\end{array}$ \\
\hline & & \multirow{2}{*}{6} & Temperatura & $\begin{array}{c}\text { Contração das } \\
\text { camadas }\end{array}$ & & Fator ambiental & 4 & Sala fechada & Termômetro na & 4 & 96 & Uso de cúpula de \\
\hline & & & ambiente & $\begin{array}{c}\text { Empenamento } \\
\text { das camadas }\end{array}$ & & $\begin{array}{l}\text { Falta de isolante } \\
\text { térmico (cúpula) }\end{array}$ & 4 & Sald tectidud & parede & 4 & 90 & acrílico \\
\hline
\end{tabular}

Na utilização da ferramenta FMEA, o resultado demonstrou um número 504 de NPR (número de prioridade de risco), no risco de haver pouca adesão da primeira camada, ou seja, a utilização do spray não se adequa ao processo, assim como a própria limpeza da máquina antes de iniciar.

Fogliatto e Ribeiro (2009) definem nove etapas para a aplicação do programa de MCC em uma organização. Mesmo não visando implementá-lo na empresa, o presente artigo mostra um esforço no sentido de cumprir algumas das etapas. As etapas, e o que já foi cumprido delas, são sumarizadas no Quadro 1.

QUADRO 1 - Estágio da empresa em relação à implementação de um programa MCC 


\begin{tabular}{|l|c|}
\hline \multicolumn{1}{|c|}{ Etapas MCC } & Estágio no cumprimento \\
\hline 1 - Escolha do comitê e equipes de trabalho & $\begin{array}{c}\text { Não foi formado um comitê para o propósito } \\
\text { específico para implementação da MCC }\end{array}$ \\
\hline 2 - Capacitação em MCC & $\begin{array}{c}\text { Os colaboradores da empresa não são } \\
\text { capacitados em MCC }\end{array}$ \\
\hline $\begin{array}{l}3 \text { - Estabelecimento dos critérios de } \\
\text { confiabilidade }\end{array}$ & $\begin{array}{c}\text { Não foram definidos os critérios de } \\
\text { confiabilidade }\end{array}$ \\
\hline 4 - Estabelecimento da base de dados & $\begin{array}{c}\text { As bases de dados ainda não foram } \\
\text { integralmente digitalizadas. }\end{array}$ \\
\hline $\begin{array}{l}5 \text { - Aplicação da FMEA e classificação dos } \\
\text { componentes }\end{array}$ & $\begin{array}{c}\text { FMEA foi aplicada. Houve um esforço } \\
\text { recente por parte da empresa nesse sentido. }\end{array}$ \\
\hline $\begin{array}{l}6 \text { - Seleção das atividades de manutenção } \\
\text { preventiva pertinentes }\end{array}$ & $\begin{array}{c}\text { Análises de riscos realizadas no presente } \\
\text { trabalho. }\end{array}$ \\
\hline $\begin{array}{l}7 \text { - Documentação das atividades de } \\
\text { manutenção }\end{array}$ & $\begin{array}{c}\text { Este relatório é uma documentação } \\
\text { importante, para trabalhos futuros. }\end{array}$ \\
\hline 8 - Estabelecimento de metas e indicadores & Não realizado \\
\hline 9 - Revisão do programa de MCC & Não realizado \\
\hline
\end{tabular}

\section{CONCLUSÃO}

Conhecer bem os equipamentos vitais da empresa é fundamental para a vida saudável da mesma. Neste sentido, foram estudadas medidas de falha da impressora Prusa Original i3 MK3, equipamento usado para impressão 3D de produtos de alta complexidade geométrica para a área biomédica.

Os dados foram coletados a partir de registros em atas e entrevistas recordatórias. A distribuição de Weibull foi a que melhor se ajustou aos dados. As análises revelaram que a maior parte das falhas na operação da impressora se dá com poucas horas de funcionamento. A confiabilidade decresce a taxas aceleradas, conforme progride a operação. As duas falhas mais frequentes são má aderência do material na mesa e o descolamento de camadas. Ambas guardam alguma relação com o gerenciamento de temperaturas ao longo do processo, sendo a subfunção mais crítica o ato de "solidificar objeto 3D".

A função foi estudada por meio de técnicas de análise de riscos, onde se obteve melhor panorama dos problemas. Dessa forma, pôde-se também esboçar ações de tratamento dos riscos levantados.

Diante do que foi apresentado, recomenda-se à empresa gerenciar melhor os dados de desempenho das máquinas, com vistas a promover melhoria contínua no processo, além de ter planejadas as ações de contingência necessárias para lidar com os problemas que aparecem no início da operação.

Ao longo do tempo, e sendo orientada para isso, a empresa saberá lidar melhor com os equipamentos que possui, explorando todo o seu potencial. Um programa de MCC, mesmo 
que implementado gradualmente e conforme as necessidades da empresa, poderia ser uma opção e fonte de trabalhos futuros.

\section{REFERÊNCIAS}

BOURELL, David L. et al. A Brief History of Additive Manufacturing and the 2009 Roadmap for Additive Manufacturing: Looking Back and Looking AheadUS. US-TURKEY Workshop On Rapid Technologies, 2009.

FOGLIATTO, Flávio Sanson; RIBEIRO, José Luis Duarte. Confiabilidade e Manutenção Industrial. 1. ed. Rio de Janeiro: Elsevier, 2009.

GOMES FERREIRA, M. G. Utilização de modelos para a representação de produtos no projeto conceitual. 1997. Dissertação (Mestrado em Engenharia Mecânica) — Universidade Federal de Santa Catarina, 1997.

LACASSE, Suzanne; BLIKRA, Lars Harald. Event Tree Analysis of Åknes rock slide hazard. Disponível em: <https://www.researchgate.net/publication/228674308>. Acesso em: 2 dez. 2018.

LEEMIS, L. Reliability: probabilistic models and statistical fatigue characteristics. In: Nova York: Prentice Hall. 1995. p. 592.

MOUBRAY, J. Reliability Centered Maintenance. In: Nova York: Industrial Press. 1997. p. 426.

PROCONF 2000. Confiabilidade de componentes: software ProConf 2000. Porto Alegre: Maxxi Gestão Empresarial, 2000.

PRUSA, Josef. Manual Prusa i3 MK33D Printing Handbook. Praga, 2018.

ROZENFELD, H. et al (2006), Gestão de Desenvolvimento de Produtos, Editora Saraiva, São Paulo.

WINTHER, Rune; JOHNSEN, Ole-Arnt; GRAN, Bjørn Axel. Security assessments of safety critical systems using HAZOPs. Computer Safety, Reliability and Security Lecture Notes in Computer Science, p. 14-24, 2001. 
APÊNDICE A - Decomposição funcional do produto

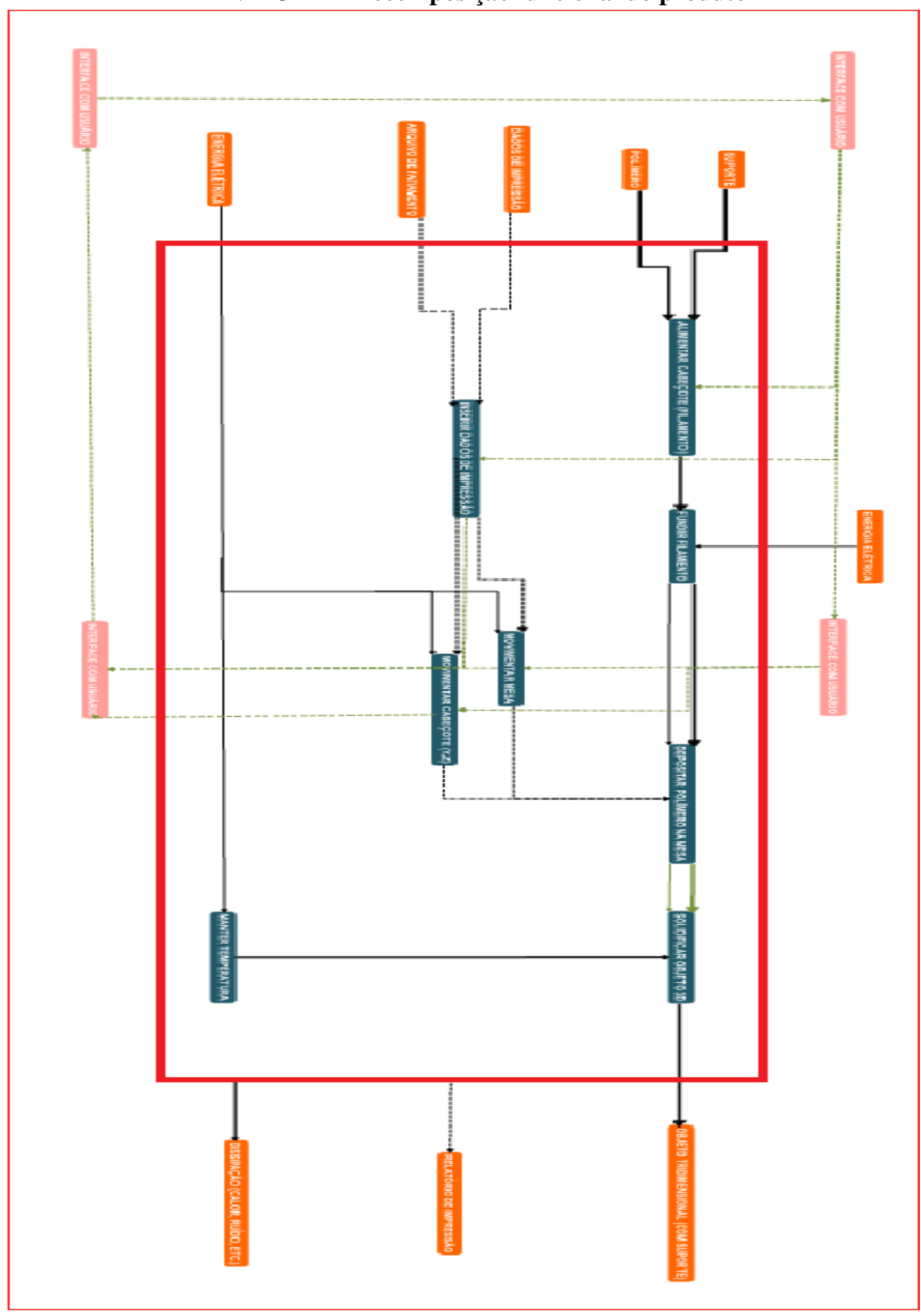

Fonte: Os autores. 